\section{Response to: 'Cutaneous adverse events with febuxostat after previous reactions to allopurinol: comment on the artcile by Singh and Clevland' by Quills et al}

We appreciate the interest and comments by Quilis et $a l^{1}$ on our recent publication. ${ }^{2}$ Quilis et al draw our attention to the incidence of cutaneous adverse reactions (CARs) with febuxostat in people who had already had reactions with allopurinol. In their study which included several practices in Spain from 2011 to $2018,15 \%$ of people developed these reactions with febuxostat ${ }^{1}$ compared with the 9\%-15\% range reported previously for similar patient populations from the USA and France. ${ }^{34}$ CARs are frequent, and are associated with significant morbidity. ${ }^{5}$ Interestingly, the rate of CARs in people newly starting febuxostat and not previously exposed to allopurinol was $2.5 \%$ in the French study, ${ }^{4}$ similar to the rate of 31 per 1000 patient-years in our study. ${ }^{2}$ So why is the risk of CARs with febuxostat increased by four-fold to six-fold (2.5\% to $9 \%-15 \%)$ in people with previous allopurinol-associated CARs compared with lower rate in the general population? Does allopurinol hypersensitivity increase the risk of hypersensitivity reactions to another urate-lowering therapy? Is there some cross-reactivity, ${ }^{6}$ despite some differences in the mechanism of action between these two medications? Are some allopurinol-associated CARs just adverse events and not hypersensitivity reactions that usually manifest as severe CARs $(\mathrm{SCARs})^{78}$ ? These are important questions to answer.

Allopurinol-associated CARs and SCARs are uncommon adverse events, and intriguing from research perspective. Given the unpredictability in occurrence and a fatal outcome in some cases, ULT-associated CARs/SCARs are important clinically. Future studies need to examine this clinical problem using various innovative approaches. Systematic studies of gene-environment-comorbidity-medication interactions are needed to solve this puzzle.

\author{
Jasvinder A Singh ${ }^{1}{ }^{1,2}$ \\ ${ }^{1}$ Department of Medicine, University of Alabama at Birmingham, Birmingham, \\ Alabama, USA \\ ${ }^{2}$ Medicine Service, Birmingham Veterans Affairs Medical Center, Birmingham, \\ Alabama, USA
}

Correspondence to Dr Jasvinder A Singh, University of Alabama at Birmingham, Birmingham, AL 35294, USA; jasvinder.md@gmail.com

Handling editor Josef S Smolen

Contributors JAS wrote the first manuscript draft, revised, read and approved the final version.

Funding The authors have not declared a specific grant for this research from any funding agency in the public, commercial or not-for-profit sectors.

Competing interests JAS has received consultant fees from Crealta/Horizon, Medisys, Fidia, UBM, Trio health, Medscape, WebMD, Clinical Care options, Clearview healthcare partners, Putnam associates, Focus forward, Navigant consulting, Spherix, Practice Point communications, the National Institutes of Health and the American College of Rheumatology. JAS owns stock options in Amarin pharmaceuticals and Viking therapeutics. JAS is on the speaker's bureau of Simply Speaking. JAS is a member of the executive of OMERACT, an organisation that develops outcome measures in rheumatology and receives arms-length funding from 12 companies. JAS serves on the FDA Arthritis Advisory Committee. JAS is the chair of the Veterans Affairs Rheumatology Field Advisory Committee. JAS is the editor and the Director of the UAB Cochrane Musculoskeletal Group Satellite Center on Network Metaanalysis. JAS previously served as a member of the following committees: member, the American College of Rheumatology's (ACR) Annual Meeting Planning Committee (AMPC) and Quality of Care Committees, the Chair of the ACR Meet-the-Professor, Workshop and Study Group Subcommittee and the cochair of the ACR Criteria and Response Criteria subcommittee.

Patient and public involvement Patients and/or the public were not involved in the design, or conduct, or reporting, or dissemination plans of this research.

Patient consent for publication Not required.

Provenance and peer review Commissioned; internally peer reviewed.

(c) Author(s) (or their employer(s)) 2020. No commercial re-use. See rights and permissions. Published by BMJ.

\section{Check for updates}

To cite Singh JA. Ann Rheum Dis Epub ahead of print: [please include Day Month Year]. doi:10.1136/annrheumdis-2020-218263

Received 11 June 2020

Accepted 12 June 2020

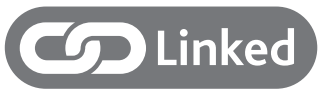

- http://dx.doi.org/10.1136/annrheumdis-2020-218226

Ann Rheum Dis 2020;0:1. doi:10.1136/annrheumdis-2020-218263

ORCID iD

Jasvinder A Singh http://orcid.org/0000-0003-3485-0006

\section{REFERENCES}

1 Quilis N, Vela P, Blanco Cáceres B, et al. Cutaneous adverse events with febuxostat after previous reactions to allopurinol: comment on the article by Singh and Cleveland. Ann Rheum Dis 2020.

2 Singh JA, Cleveland JD. Hypersensitivity reactions with allopurinol and febuxostat: a study using the Medicare claims data. Ann Rheum Dis 2020;79:529-35.

3 Chohan S. Safety and efficacy of febuxostat treatment in subjects with gout and severe allopurinol adverse reactions. J Rheumatol 2011;38:1957-9.

4 Bardin T, Chalès G, Pascart T, et al. Risk of cutaneous adverse events with febuxostat treatment in patients with skin reaction to allopurinol. A retrospective, hospital-based study of 101 patients with consecutive allopurinol and febuxostat treatment. Joint Bone Spine 2016;83:314-7.

5 Svensson CK, Cowen EW, Gaspari AA. Cutaneous drug reactions. Pharmacol Rev 2001;53:357-79.

6 Pichler WJ, Daubner B, Kawabata T. Drug hypersensitivity: flare-up reactions, crossreactivity and multiple drug hypersensitivity. J Dermatol 2011;38:216-21.

7 Duong TA, Valeyrie-Allanore L, Wolkenstein P, et al. Severe cutaneous adverse reactions to drugs. Lancet 2017;390:1996-2011.

8 Roujeau JC, Stern RS. Severe adverse cutaneous reactions to drugs. N Eng/ J Med 1994;331:1272-85. 